\title{
THE
}

\section{A pharmacist-driven academic detailing program to increase adult pneumococcal vaccination}

Aisling R. Caffrey

University of Rhode Island, aisling_caffrey@uri.edu

M. DeAngelis

University of Rhode Island, jdeangelis7915@uri.edu

Kristina E. Ward

University of Rhode Island, kward@uri.edu

Katherine Kelly Orr

University of Rhode Island, kellyo@uri.edu

Halex Jhisorrill additional works at: https://digitalcommons.uri.edu/php_facpubs

The University of Rhode Island Faculty have made this article openly available.

Please let us know how Open Access to this research benefits you.

This is a pre-publication author manuscript of the final, published article.

Terms of Use

This article is made available under the terms and conditions applicable towards Open Access

Policy Articles, as set forth in our Terms of Use.

\section{Citation/Publisher Attribution}

Caffrey, A.R., DeAngelis, J.M., Ward, K.E., Orr, K.K., Morrill, H.J., Gosciminski, M., \& LaPlante, K.L. (2017). A pharmacist-driven academic detailing program to increase adult pneumococcal vaccination. Journal of the American Pharmacists Association, 58(3), 303-310. doi: 10.1016/j.japh.2017.08.010

Available at: http://dx.doi.org/10.1016/j.japh.2017.08.010 


\section{Authors}

Aisling R. Caffrey, M. DeAngelis, Kristina E. Ward, Katherine Kelly Orr, Haley J. Morrill, Michael Gosciminski, and Kerry L. LaPlante 


\section{A pharmacist-driven academic detailing program to increase adult pneumococcal vaccination}

Aisling R. Caffrey, Ph.D., M.S. ${ }^{\text {a,b,c }}$, Jennifer M. DeAngelis, B.A. ${ }^{a}$, Kristina E. Ward, Pharm.D., BCPS ${ }^{a}$, K. Kelly Orr, Pharm.D., AE-C ${ }^{a}$, Haley J. Morrill, Pharm.D. ${ }^{a, b}$, Michael Gosciminski, M.T., MPH ${ }^{\mathrm{d}}$, Kerry L. LaPlante, Pharm.D., FCCP ${ }^{\mathrm{a}, \mathrm{b}, \mathrm{e}}$, and the Rhode Island Pharmacy Pneumococcal Vaccination Education Group

aUniversity of Rhode Island, Department of Pharmacy Practice, College of Pharmacy, Kingston, Rhode Island

${ }^{b}$ Veterans Affairs Medical Center, Rhode Island Infectious Diseases (RIID) Research Program and Center of Innovation in Long Term Services and Supports, Providence, Rhode Island 'Brown University School of Public Health, Providence, RI

${ }^{\mathrm{d}}$ Rhode Island Department of Health, Center for Acute Infectious Disease Epidemiology, Providence, Rhode Island

eWarren Alpert Medical School of Brown University, Division of Infectious Diseases, Providence, Rhode Island

Author identification

Aisling R. Caffrey, Ph.D., M.S., is Assistant Professor, College of Pharmacy, University of Rhode Island, Kingston, Rhode Island; Director of Outcomes Research, Rhode Island Infectious Diseases (RIID) Research Program and Investigator, Center of Innovation in Long Term Services and Supports, Providence Veterans Affairs Medical Center, Providence, Rhode Island; Adjunct Assistant Professor of Health Services, Policy and Practice, Brown University School of Public Health, Providence, Rhode Island. 
Jennifer M. DeAngelis, B.A. is Program Coordinator, Rhode Island Infectious Diseases Research Program (RIID), College of Pharmacy, University of Rhode Island, Kingston, Rhode Island.

Kristina E. Ward, Pharm.D., BCPS, is Clinical Professor and Director of Drug Information Services, College of Pharmacy, University of Rhode Island, Kingston, Rhode Island.

Kelly Orr, Pharm.D., AE-C, is Clinical Professor, Director of Student and Academic Affairs, College of Pharmacy, University of Rhode Island, Kingston, Rhode Island.

Haley J. Morrill, Pharm.D., is Investigator, Rhode Island Infectious Diseases (RIID) Research Program and Center of Innovation in Long Term Services and Supports, Providence Veterans Affairs Medical Center, Providence, Rhode Island; Adjunct Clinical Assistant Professor, College of Pharmacy, University of Rhode Island Kingston, Rhode Island.

Michael Gosciminski, M.T., MPH, is Senior Public Health Epidemiologist, Center for Acute Infectious Disease Epidemiology, Rhode Island Department of Health, Providence, Rhode Island.

Kerry L. LaPlante, Pharm.D., FCCP is Professor of Pharmacy, College of Pharmacy, University of Rhode Island, Kingston, Rhode Island; Director, Antimicrobial Stewardship Program and Pharmacy Training Fellowship and Rhode Island Infectious Diseases (RIID) Research Program, Providence Veterans Affairs Medical Center, Providence, Rhode Island; Adjunct Professor of Medicine, Warren Alpert Medical School of Brown University, Division of Infectious Diseases, Providence, Rhode Island.

Rhode Island Pharmacy Pneumococcal Vaccination Education Group 
Jeffrey P. Bratberg, Pharm.D., is Clinical Professor, College of Pharmacy, University of Rhode Island, Kingston, Rhode Island.

Michelle L. Caetano, Pharm.D., BCPS, BCACP, CDOE, CVDOE, is Clinical Assistant Professor, College of Pharmacy, University of Rhode Island, Kingston, Rhode Island.

Brett Feret, Pharm.D, is Clinical Professor and Director of Experiential Education, College of Pharmacy, University of Rhode Island, Kingston, Rhode Island.

Virginia A. Lemay, Pharm.D., CDOE, CVDOE, is Clinical Associate Professor, College of Pharmacy, University of Rhode Island, Kingston, Rhode Island.

\section{Correspondence}

Corresponding Author:

Kerry L. LaPlante, Pharm.D., FCCP

Professor, University of Rhode Island, College of Pharmacy

7 Greenhouse Rd, Suite 295A, Kingston, RI 02881

Tel: 401.874.5560; Fax: 401.457.3305; e-mail: KerryLaPlante@uri.edu

Alternate Corresponding Author:

Aisling R. Caffrey, PhD, MS

Assistant Professor, University of Rhode Island

7 Greenhouse Road, Kingston, RI 02881

Tel: 401-874-5320; e-mail: Aisling Caffrey@uri.edu

Potential conflicts of interest disclosure 
Aisling Caffrey has received research funding from Pfizer, Merck (Cubist), and The Medicines Company. Haley Morrill is supported in part by a Career Development Award, Department of Veterans Affairs, and has received research funding from Merck (Cubist). Kelly Orr and Jennifer DeAngelis have received research funding from Pfizer. Kerry LaPlante has received research funding or acted as a scientific advisor for Allergan, Bard, Merck (Cubist), Ocean Spray, Pfizer, and The Medicines Company. The other authors have no conflicts to disclose.

\section{Acknowledgements}

The views expressed are those of the authors and do not necessarily reflect the position or policy of the University of Rhode Island or United States Department of Veterans Affairs. We appreciate the assistance of Kayla Babcock, Diane Gomes, Pharm.D., and Thomas J. Kalista, Pharm.D. with academic detailing. From the University of Rhode Island Pharmacy Outreach Program, we appreciate the contributions of Rita Marcoux, Noemi Ramos-Desimone, and Nancy Tortolani. From the Rhode Island Department of Health, we appreciate the assistance of

Dr. Uptala Bandy and Daniela Quilliam (pneumococcal case report data), Kathleen Taylor and Samara Viner-Brown (hospital discharge data), as well as Hanna Kim and Tara Cooper (vaccination data).

\section{Funding}

This work was supported, in part, by a grant from Pfizer's Office of Independent Grants for Learning \& Change. The funding source did not have any involvement in the collection, analysis, or interpretation of data; in the writing of the report; or in the decision to submit the article for publication.

\section{Previous presentations}


Presented previously at the American Pharmacists Association (APhA) Annual Meeting and Exposition 2017, San Francisco, CA, March 26 $6^{\text {th }}, 2016$.

\section{Abstract word count: 288}

Manuscript word count: 3,720

\section{Keywords}

pneumococcal infections, pneumococcal vaccines, immunization providers, academic detailing, pharmacists, community pharmacy

\section{$\underline{\text { Author contributions }}$}

\begin{tabular}{|l|l|}
\hline $\begin{array}{l}\text { Substantial contributions to the conception and design of } \\
\text { the work, or the acquisition, or analysis and } \\
\text { interpretation of data; AND }\end{array}$ & $\begin{array}{l}\text { Design: ARC, KEW, KO, HJM, KLL } \\
\text { Data: ARC, JMD, MG, KLL, Group (JPB, } \\
\text { MLC, BF, VL) }\end{array}$ \\
\hline $\begin{array}{l}\text { Drafting the manuscript or revising it critically for } \\
\text { important intellectual content; AND }\end{array}$ & $\begin{array}{l}\text { ARC, JMD, KEW, KO, HJM, MG, KLL, } \\
\text { Group (JPB, MLC, BF, VL) }\end{array}$ \\
\hline $\begin{array}{l}\text { Final approval of the version to be published; AND } \\
\text { questions related to the accuracy or integrity of any part } \\
\text { of the work are appropriately investigated and resolved. }\end{array}$ & Group (JPB, MLC, BF, VL) \\
\hline $\begin{array}{l}\text { Accountable for all aspects of the work , KO, HJM, MG, KLL, } \\
\text { Group (JPB, MLC, BF, VL) }\end{array}$ \\
\hline
\end{tabular}




\section{Abstract}

Objectives: To describe our statewide pharmacist-led, education campaign to increase knowledge and awareness of pneumococcal immunization recommendations.

Setting: Immunization providers and residents in the State of Rhode Island.

Practice description: A clinical pathway (i.e., decision-support tool) was developed to educate healthcare professionals about appropriate indications, administration schedules, and frequently asked questions for the two different adult pneumococcal vaccines. Academic detailing and distribution of the clinical pathway to healthcare professionals was conducted across Rhode Island. Community outreach activities included radio ads, as well as distribution of patient handouts and wallet cards at community events.

Practice innovation: To our knowledge, this was the first statewide pharmacist-driven academic detailing and community outreach campaign to promote adult pneumococcal vaccination.

Evaluation: Academically-detailed immunization providers received a six-question survey. Pneumococcal disease rate differences between the study periods were evaluated with Fisher's exact tests, while changes in vaccination were assessed with chi-square tests.

Results: From November 2013 through July 2015, our academic detailers visited and/or distributed our vaccination pathway materials to over 400 practice sites across Rhode Island, including $68 \%$ of community pharmacies and all adult acute care hospitals. Of the 413 surveys completed, 92\% of respondents agreed that their knowledge of the PCV13 and PPSV23 vaccines had improved. Pneumococcal vaccination increased significantly (absolute difference 3.9\%, percent change in proportion 5.4\%; $p=0.01$ ) and pneumococcal disease decreased significantly between the pre-intervention and intervention periods $(-2.74 / 10,000$ discharges, $95 \%$ confidence interval $[\mathrm{Cl}]-5.15,-0.32 ; p=0.02)$. Invasive pneumococcal disease decreased by 21 cases per $1,000,000$ population per year between the pre-intervention and post-intervention periods (95\% $\mathrm{Cl}-42.25,0.14 ; p=0.05)$. 
Conclusion: Our statewide pharmacist-driven pneumococcal vaccination educational outreach program resulted in favorable provider feedback relative to knowledge change and perceptions. Vaccination increased while pneumococcal disease decreased during the study period. 


\section{Key Points}

\section{Background}

- Pneumococcal vaccination remains well below the Healthy People 2020 goal of $90 \%$ in older adults, both nationally and in Rhode Island.

- Prior to the intervention, Rhode Island had a higher burden of invasive pneumococcal disease than the rates observed regionally or nationally.

- Pneumococcal vaccination recommendations have undergone several changes in recent years, including expanded indications for vaccination.

\section{Findings}

- Pharmacist-led academic detailing sessions improved self-reported immunization provider knowledge of PCV13 and PPVSV23 vaccination recommendations, resulting in intentions to apply this knowledge in clinical practice and expected changes in their vaccination practices.

- Since implementing our academic detailing and community outreach intervention in Rhode Island, (1) invasive pneumococcal disease decreased despite increases in New England during the same time period, (2) pneumococcal vaccination increased significantly, and (3) there were significantly fewer pneumococcal disease hospital discharges. 


\section{Introduction}

More than half of pneumococcal disease in older adults occurs in non-vaccinated patients who have an indication for pneumococcal vaccination. ${ }^{1,2}$ Moreover, an estimated 67 million at-risk individuals in the United States (US) have not yet been vaccinated. ${ }^{1,2}$ This data is extremely concerning because patients with Advisory Committee on Immunization Practices (ACIP) indications for pneumococcal vaccination are twice as likely to die as those without indications if they develop invasive pneumococcal disease. ${ }^{3}$ Despite this grave reality, and efforts to improve national pneumococcal vaccination rates among populations that should be vaccinated, vaccinations rates rarely reach $75 \% .^{4-6}$ Pneumococcal vaccination in adults aged 65 years and older has remained relatively stable over the past several years, however, it is still well below the Healthy People 2020 goal of $90 \% .^{4}$

A significant challenge with adult vaccinations, as opposed to childhood vaccinations, is awareness of vaccination indications among immunization providers and patients. ${ }^{7-10}$ This is particularly problematic in adult populations since vaccine status assessment by healthcare providers is not routine, patients often receive care at multiple locations (indicating care may not be coordinated), and patients may be unaware of their immunization status. ${ }^{7-10}$ Further, pneumococcal vaccination recommendations have undergone several changes in recent years and can be complex depending on the patient's age, medical conditions, and previous pneumococcal vaccination status. ${ }^{11-15}$

\section{Objectives}

We developed a statewide pharmacist-led, education campaign utilizing academic detailing and patient outreach to improve adult pneumococcal rates by increasing knowledge and awareness of pneumococcal immunization recommendations. To assess the effectiveness of our approach for improving pneumococcal vaccination in Rhode Island through education, we evaluated a 
range of outcomes, including changes in vaccination rates, invasive pneumococcal infections, and pneumococcal pneumonia, as well as provider feedback on academic detailing.

\section{Setting}

Our education campaign targeted immunization providers and residents of Rhode Island. Immunization providers were educated in the practice setting, as well as at conferences and meetings. Patients were educated at community events and through radio announcements.

\section{Practice description}

Decision pathway and educational materials

The pharmacist-led academic detailing team developed a vaccination pathway (i.e., clinical decision-support tool) designed to address the complex pneumococcal vaccine administration schedules and corresponding indications, which served as a central component for immunization provider education. The pathway was developed based on the Advisory Committee on Immunization Practices (ACIP) adult pneumococcal vaccination recommendations, the Center for Disease Control and Prevention, and the Infectious Disease Society of America (IDSA), along with information from the Immunization Action Coalition and prescribing information for both types of adult pneumococcal vaccinations (PPSV23 and PCV13; see Supplementary File, also available at http://web.uri.edu/antimicrobial-stewardship/infections-by-organism/). ${ }^{11-15}$ After initial pathway development, local infectious disease specialists were asked to provide critical analysis and feedback to help ensure the final pathway provided complete information in an easy-to-follow format. When necessary, the pathway was updated to reflect the most current guideline recommendations. The vaccination pathway was reviewed and approved by the Rhode Island Department of Health and copyrighted by the University of Rhode Island Office of Intellectual Property and Economic Development. 
The four-page pathway document was laminated and held together by a corner ring for durability and accessibility in the clinical setting. The pathway included the adult pneumococcal vaccination recommendations and schedule for both PPSV23 and PCV13, medical conditions requiring pneumococcal vaccination, facts about pneumococcal disease, frequently asked questions about pneumococcal vaccination, package insert information on both types of pneumococcal vaccinations, as well as contraindications, side effects, and precautions. Contact information for the major insurance carriers in Rhode Island was also provided.

A patient vaccination wallet card and pneumococcal vaccination patient information handout were also created. The wallet card included space to record vaccination status for multiple adult immunizations and important medical information. A wallet card sleeve was incorporated to protect the wallet card and included a reminder to "please carry this with you and show to your healthcare professional". The wallet card was approved by the Rhode Island Department of Health and the Ocean State Adult Immunization Coalition. An educational patient handout was developed and included information on the dangers of pneumococcal disease, who should be vaccinated, and prompted patients to contact their immunization providers to get vaccinated. The handout was developed using resources from the Immunization Action Coalition, the National Foundation for Infectious Diseases, and scholarly articles. The wallet card, wallet card sleeve, and patient handout were all printed in English and in the 5 most common foreign languages spoken in Rhode Island since $5.7 \%$ of households in Rhode Island are linguistically isolated.

\section{Academic detailing}

Implementation, immunization providers

In an effort to introduce our vaccination pathway to immunization providers throughout the state, our team (Authors JMD, KEW, KO, KLL, Group [JPB, MLC, BF, VL], Acknowledgements [TJK, RM, NRD]) attended 22 events with pharmacist, physicians, and nurse attendees. Presentations 
on our vaccination pathway were made to the Rhode Island Department of Health Flu Task Force, Rhode Island Certified Diabetes Outpatient Educators, Ocean State Adult Immunization Coalition, Wellness Company Nurses Protocol Meeting, Seminar by the Sea Northeast Regional Continuing Education Conference for Pharmacists, Rhode Island Pharmacists Foundation, Coastal Medical of Rhode Island, Rhode Island Department of Health Nurses Conference, and Economic Burden of Vaccine Preventable Diseases in Rhode Island. Additionally, we mailed copies of our vaccination pathway to hospitals and clinics in both Rhode Island and surrounding states. Events and mailings were either planned based on outreach efforts by the project team or by request of the event host or facility.

All materials distributed during our statewide academic detailing and community outreach campaign were made available for download from the URI Drug Information Services website (http://web.uri.edu/pharmacy/drug-info/) to ensure continued access to the vaccination pathway and patient handouts and to make the materials available to a wider audience. An email with the link to the website was sent to approximately 50 immunization providers in the state.

Implementation, community pharmacies

A list of all CVS, Rite Aid, Target, and Walgreens pharmacies in Rhode Island was compiled. The URI College of Pharmacy has full-time faculty, adjunct faculty, and preceptors with clinical practice sites in community pharmacies across the state. The College's relationships with these pharmacies enabled us to present our pneumococcal vaccination pathway and conduct academic detailing at 68\% (121/177) of Rhode Island pharmacies from November 2013 through July 2015. The academic detailers included URI faculty, a community pharmacy resident, and a student pharmacist. Various academic detailing methods were used to reach as many immunization providers as possible in the state. A 1-to-1, face-to-face approach was utilized at all of the CVS, Rite Aid, and Target pharmacy sites visited. Sessions lasted approximately 15 minutes, and each 
participant was provided education on how to use the pneumococcal vaccination pathway, vaccination indications, and the recommended schedule of vaccination. Academic detailing for Walgreens pharmacies consisted of a 20-minute presentation at the Walgreens District meeting of 70 pharmacy managers. Academic detailing sessions also occurred during two Rite Aid district meetings (23 stores).

\section{$\underline{\text { Patient outreach }}$}

To further improve communication and coordination between patients and their immunization providers, a Public Service Announcement (PSA) was developed in collaboration with the Rhode Island Department of Health and Ocean State Adult Immunization Coalition, which aired in English and Spanish on Rhode Island radio stations: "Do you have diabetes or asthma? Do you smoke? Are you over 65 years of age? If you answered yes to even one of these questions, you are at increased risk for bacterial pneumonia. Bacterial pneumonia is an infection of the lungs. It's a dangerous disease that could send you to the hospital. In some cases, it can even be deadly. The good news is that you can protect yourself. Ask your doctor or pharmacist about the vaccine that protects against bacterial pneumonia. Vaccination - it's your best defense. Sponsored by the University of Rhode Island College of Pharmacy and the Rhode Island Department of Health". Our target audience for the PSA was adults 65 years and older, and based on demographics provided by the advertising company, six radio stations were chosen. The PSA aired a total of 227 times in December 2014.

To reach patients of diverse backgrounds throughout Rhode Island, the study team and the URI Pharmacy Outreach Program attended over 100 public health events over the intervention period. Events included public health fairs, such as the Feed 1,000 Rhode Islanders event for two consecutive years, brown bag events, support groups, and educational programs held at senior centers, senior housing, and community centers. Wallet cards, patient handouts, and sticks of lip 
balm promoting pneumococcal vaccination were distributed to attendees. At several events, formal presentation about pneumococcal disease and pneumococcal vaccination were made to attendees.

\section{Practice innovation}

To our knowledge, this is the first statewide pharmacist-driven academic detailing and community outreach campaign to promote adult vaccination. Academic detailing is "university or noncommercial-based educational outreach which involves face-to-face education to prescribers by trained healthcare professionals". ${ }^{16,17}$ The goal of academic detailing is to provide education consistent with medical evidence and guidance documents. ${ }^{16,17}$ With the complexity of recommendations for pneumococcal vaccination, development of an easy-to-understand pathway and corresponding educational materials served as the backbone for our academic detailing efforts. Prior to pathway development, implementation of the ACIP recommendations was difficult due to a lack of public and provider knowledge, electronic medical record systems that did not automatically recommend the correct vaccine, and perceived and actual financial/reimbursement limitations, mainly from the primary payer for older adults, Medicare.

\section{Evaluation}

$\underline{\text { Immunization provider survey }}$

After academic detailing sessions, each provider participant was requested to take an anonymous 6 question survey about the effectiveness of their detailing session (see Supplementary File). Surveys were either submitted electronically via Survey Monkey on an iPad, or paper surveys were collected in a sealed envelope, depending on immunization provider preference. Domains of survey measurement included content understanding, educational material ease of use, satisfaction with the academic detailing session, confidence in applying the new knowledge in practice, and intention to utilize the pathway and change vaccination practices. Each question 
followed a 5-point Likert scale, from strongly disagree $=1$ to strongly agree $=5$. We assessed the percent agreeing with each question ( $5=$ strongly agree, $4=$ agree). Health profession and setting were collected in the survey and question responses were compared between groups using the chi-square or Fisher's exact tests as appropriate.

\section{$\underline{\text { Pneumococcal vaccination and infections }}$}

Vaccination

Pneumococcal vaccination was determined from the Behavioral Risk Factor Surveillance System (BRFSS), a national, cross-sectional survey which collects information about health behaviors, disease, and preventive services, such as vaccination. ${ }^{6,18}$ We evaluated the percentage of adult respondents 65 years and older who have ever had a pneumonia vaccination in Rhode Island and the US. Percent changes in the proportion of respondents answering "yes" to this question over the study period were assessed, as were absolute differences. Rhode Island BRFSS count data was obtained from the Rhode Island Department of Health, and US percentages were obtained from the Centers for Disease Control and Prevention BRFSS website.

Invasive pneumococcal disease, case reports

The goal of vaccination is to prevent morbidity and mortality, particularly invasive disease. As such, we assessed changes in invasive pneumococcal disease in Rhode Island. Invasive pneumococcal disease has been a reportable disease nationally since $2010 .{ }^{19}$ Invasive disease is confirmed by isolation of pneumococcus from blood, cerebrospinal fluid, pericardial fluid, pleural fluid, peritoneal fluid, joint fluid, or other normally sterile site. Due to seasonal variations in pneumococcal disease, calendar years were used to define the study periods. The preintervention period was January 1 through December 31, 2013, the intervention period was January 1, 2014 through December 31, 2015, and the post-intervention period was January 1 through December 31, 2016. Due to the use of calendar years, the intervention period included 
a 5 month wash-out period without active academic detailing or community outreach activities which concluded in July 2015. Changes were compared between the pre-intervention and intervention periods, and pre-intervention and post-intervention periods. We collected the number of cases of invasive disease from Notifiable Disease and Mortality Tables from Morbidity and Mortality Weekly Reports. ${ }^{20}$ Notifiable disease reports collected by individual states and territories are sent to the Centers for Disease Control and Prevention, which are then published as weekly disease rates and compiled into annual reports. ${ }^{20}$ Final reports and provisional reports were used to calculate cases per study period (final report for 2016 not expected until late 2017). ${ }^{20}$ Population estimates, provided as estimates as of July 1 each year, were obtained from the United States Census Bureau. ${ }^{21}$

\section{Pneumococcal disease, hospital discharge data}

We assessed pneumococcal disease from hospital discharge data collected by the Rhode Island Department of Health. Discharge data is captured from 5 teaching hospitals providing general acute care, 6 other general acute-care hospitals, 2 psychiatric teaching hospitals, and 1 rehabilitation hospital. International Classification of Disease, $9^{\text {th }}$ revision (ICD-9) diagnosis codes were used to identify pneumococcal disease: pneumonia 481, bacteremia 038.2, and meningitis 320.1. Due to the switch from ICD-9 to ICD-10, hospital discharge data was only available through September 2015.

\section{Statistical analysis}

Discharge rates per 10,000 discharges and per 10,000 bed days were calculated. Invasive disease was calculated per 1,000,000 population. Using OpenEpi, changes in vaccination (for Rhode Island), infection type, inpatient mortality, and pneumococcal disease rate differences between the study periods were evaluated with chi-square, Fisher's exact, or t-tests, as appropriate. $^{22}$ 


\section{Ethics approval}

This project was reviewed by the Institutional Review Board of the University of Rhode Island and was determined to be exempt according to federal regulations 45 CFR 46.101(b)(2) and 45 CFR 46.101(b)(4).

\section{Results}

Academic detailing

Academic detailing was assessed with surveys of licensed immunization providers. Overall, immunization providers found the academic detailing sessions to be effective with easy to understand materials (Tables 1 and 2). Most immunization providers agreed or strongly agreed (92\%) that their knowledge of identifying which patient populations meet the recommendations for PCV13 or PPVSV23 improved. Providers intended to apply the knowledge in their clinical practice (83\%), and expected their vaccination practices to change as a result of the academic detailing and education materials (73\%). Almost $90 \%$ of immunization providers found the educational materials easy to understand. As compared with agreement in the community setting (Table 1$)$, there was significantly $(p<0.05)$ less agreement with the questions in both the hospital setting (Q2-Q6) and the private practice setting (Q1, Q3-Q5). As compared with agreement reported by pharmacists (Table 2$)$, there was significantly $(p<0.05)$ less agreement with all of the questions as reported by nurses.

Of the 74 respondents who provided additional comments, $62 \%$ gave positive feedback regarding the detailer and/or materials, such as "Great flow chart, easy to read, very informative" and "[Academic detailer] did a great job explaining all the information! I feel that I am able to really put this new information into good practice." Of those providing positive feedback, $78 \%$ were pharmacists. A quarter of the respondents providing additional comments found the pathway 
and/or detailing session to be confusing, complicated, or lacking information (18/73), such as "Difficult to follow and had to flip back and forth" and "I would like a better description on the 2 indications for Prevnar". Of those that found the material or session confusing, $72 \%$ were nurses. Other respondents noted that they do not vaccinate (3\%) or were already implementing the pneumococcal vaccination recommendations (4\%).

\section{Pneumococcal vaccination and infections}

Vaccination

In the US, the percentage of adults 65 years and older who had ever received pneumococcal vaccination increased from $69.5 \%$ in 2013 to $72.5 \%$ in 2015 (absolute difference 3.0\%, percent change in proportion 4.3\%). In Rhode Island, pneumococcal vaccination increased significantly from 72.4\% (95\% confidence interval [Cl] 69.7-75.1) in 2013 to 76.3\% (95\% Cl 73.8-78.8) in 2015 (absolute difference 3.9\%, percent change in proportion $5.4 \% \%$; $=0.01$ ).

\section{Pneumococcal disease}

After our pharmacist-led academic detailing program, annual rates of pneumococcal disease declined significantly by 2.8 per 10,000 discharges (Table $3 ; p=0.02$ ). This resulted in 0.5 fewer bed days of care per 10,000 bed days $(p=0.04)$. Rates of pneumococcal disease were largely driven by pneumococcal pneumonia over the entire study period (79.2\%). Compared to the preintervention period, the proportion of pneumococcal disease discharges in Rhode Island with pneumococcal pneumonia decreased significantly in the intervention period $(86.0 \%$ vs $75.5 \%$; $p=0.01)$, and the proportion with pneumococcal bacteremia increased ( $24.3 \%$ vs $33.6 \% ; p=0.06)$. Inpatient mortality was significantly lower in the intervention period compared to the preintervention period ( $8.8 \%$ vs $3.6 \% ; \mathrm{p}=0.03)$. 
Before our academic detailing program began, the annual rate of invasive pneumococcal disease was higher in Rhode Island (72/1,000,000 persons) than in New England (47/1,000,000 persons) or the United States $(53 / 1,000,000$ persons), as shown in Table 4 . While the annual rate of invasive pneumococcal disease increased significantly in New England over the study period (74/1,000,000 persons; rate difference $26.35,95 \% \mathrm{Cl} 20.73,31.98 ; \mathrm{p}<0.0001)$, it decreased in both the United States $(45 / 1,000,000$ persons; rate difference $-7.78,95 \% \mathrm{Cl}-8.87,-6.70$; $\mathrm{p}<0.0001)$ and Rhode Island (51/1,000,000 persons; rate difference $-21.06,95 \% \mathrm{Cl}-42.25,0.14$; $\mathrm{p}=0.05)$. Comparing rates in Rhode Island to those in the US overall, Rhode Island had more cases of invasive disease per year in the pre-intervention period (rate difference 19.47, $95 \% \mathrm{Cl}$ $3.22,35.71 ; p=0.006)$. In the post-intervention period, the Rhode Island rate was similar to that of the US (rate difference $6.19,95 \% \mathrm{Cl}-7.46,19.84 ; \mathrm{p}=0.34$ ).

\section{Discussion}

Since the implementation of our statewide academic detailing and community outreach intervention to increase pneumococcal vaccination among older adults, vaccination in the state increased significantly, and we observed other signals which infer increased vaccination, including a 5\% decline in inpatient mortality among patient with pneumococcal disease. ${ }^{23-25}$ Additionally, we observed significant decreases in pneumococcal disease. Though the decline in invasive pneumococcal disease was at the boundary of statistical significance $(p=0.05)$, Rhode Island went from having nearly 20 more cases of invasive disease per year than the overall rate for the United States, to having a similar rate in the post-intervention period. Further, although there was a significant increase in cases of invasive pneumococcal disease in New England, we observed a decrease in Rhode Island.

According to a recent systematic review, most academic detailing interventions have generally targeted one specific provider type (40.0\% physician, $33.7 \%$ pharmacist, $27.4 \%$ nurse), fewer 
studies have implemented a multifaceted approach targeting various providers (23.2\%), and only about one third included community outreach (31.1\%),. ${ }^{26}$ Further, more than half of studies only measured one outcome (56.6\%), and a majority of those measured clinician behavior (91.5\%). ${ }^{26}$ Our intervention was multifaceted both in the intervention and measurement of outcomes. Few studies have evaluated the impact of academic detailing on adult vaccinations, and fewer assessed the impact on actual vaccination or diseases rates. ${ }^{27,28}$ One randomized controlled study to increase the use of preventive services found that academic detailing and peercomparison feedback to physicians was no more effective in increasing influenza and pneumococcal vaccination than educational reminders. ${ }^{29}$ However, academic detailing has been effective for other medication management initiatives. ${ }^{30}$

Our statewide academic detailing efforts, along with the supporting pathway and educational materials, impacted immunization providers' perception of knowledge about pneumococcal vaccination. Our survey results demonstrated that the academic detailing efforts increased immunization providers' perceived ability to identify patients eligible for pneumococcal vaccination and many providers indicated that the new knowledge would be incorporated into their clinical practice. Provider survey results suggests the education through academic detailing with supporting materials was effective for immunization providers in community settings but that improvements could be made in regards to hospital and nurse education.

Pharmacists consistently noted the pneumococcal pathway materials assisted them and clarified questions they had regarding recommendations for which patient populations should receive the PPSV23 and PCV13 and the administration schedules. Individual 1-to-1 approaches were mainly implemented to reach as many pharmacists as possible in their practice settings. The academic detailers remarked on the difficulties in providing consistent academic detailing at community pharmacies. Academic detailing in this setting is often challenging because of constraints on the 
pharmacists' time to step away from the workflow and this is dependent on prescription volume as well as additional professional staffing at the pharmacy. A large group meeting of pharmacy managers proved to be an efficient forum, allowing pharmacists the time to adequately review the materials and pose questions of the detailer.

\section{Limitations}

First, national vaccination recommendations were updated over the study period and meant outdated materials were in circulation. When this occurred, academic detailing was repeated in community pharmacies, adding considerable time to the project and effort from the academic detailers. The vaccination pathway did include the URI Drug Information Services website so that immunization providers could access and download the most recent version of the pathway. Second, to account for seasonal changes in pneumococcal disease, the study periods were divided by calendar year, so the intervention period included a 5 month wash-out period without active academic detailing or community outreach activities. Though academic detailing began in November 2013, few sessions were conducted due to the holidays. As immediate effects on statewide pneumococcal disease rates from these sessions were not expected, categorization by calendar year was considered appropriate. Additionally, due to the switch from International Classification of Diseases $9^{\text {th }}$ Edition to $10^{\text {th }}$ Edition in October 2015 , the codes for pneumococcal disease changed, and pneumococcal hospital discharges from the last quarter of 2015 onward were not included as rate differences may have been artefactual. Therefore, the intervention period for pneumococcal hospital discharges ended in September 2015. Third, though community pharmacies received two academic detailing sessions, different pharmacists may have participated in the detailing sessions, and as such, we were not able to follow-up with immunization providers to determine use of the academic detailing material in the practice or whether the pathways changed their immunization practices. Fourth, we could not calculate a response rate for the academic detailing survey. These results may be limited by response bias, 
since the exact number of attendees was not known for some academic detailing sessions, and some pharmacists may have received academic detailing on multiple occasions. Fifth, we attempted to collect vaccination data from several sources, other than BRFSS, however, we were not able to obtain these data. Lastly, we were not able to control for other factors that may have influenced vaccination practices over time, including vaccine advertisements or internal immunization provider policies to increase pneumococcal vaccination.

\section{Conclusions}

Our statewide pharmacist-driven campaign to increase adult pneumococcal vaccination through academic detailing to immunization providers and community outreach efforts resulted in increased self-reported provider knowledge regarding the pneumococcal vaccine. During the study period, we observed increases in vaccination and decreases in pneumococcal disease in Rhode Island. 


\section{References}

1. Greene CM, Kyaw MH, Ray SM, et al. Preventability of invasive pneumococcal disease and assessment of current polysaccharide vaccine recommendations for adults: United States, 2001-2003. Clin Infect Dis 2006;43:141-150.

2. Pneumococcal Disease: Fast Facts. 2015. Available at: http://www.cdc.gov/pneumococcal/about/facts.html. Accessed June 2016.

3. Robinson KA, Baughman W, Rothrock G, et al. Epidemiology of invasive Streptococcus pneumoniae infections in the United States, 1995-1998: Opportunities for prevention in the conjugate vaccine era. JAMA 2001;285:1729-1735.

4. U.S. Department of Health \& Human Services. Healthy People 2020 Objectives. Available at: https://www.healthypeople.gov/2020/topics-objectives/topic/immunization-andinfectious-diseases/objectives. Accessed June 2016.

5. Centers for Disease Control and Prevention. Early Release of Selected Estimates Based on Data From the 2015 National Health Interview Survey. Available at: $\quad$ http://www.cdc.gov/nchs/data/nhis/earlyrelease/earlyrelease201605 05.pdf. Accessed June 2016.

6. Centers for Disease Control and Prevention. BRFSS Prevalence \& Trends Data. Available at: http://wwwdev.cdc.gov/brfss/brfssprevalencel. Accessed May 2017.

7. National Vaccine Advisory Committee. A Pathway to Leadership for Adult Immunization: Recommendations of the National Vaccine Advisory Committee. Public Health Rep 2012 (Supp 1): 1-42.

8. The Robert Wood Johnson Foundation. Adult Immunization: Shots to Save Lives. Washington, DC: February, 2010.

9. Johnson DR, Nichol KL, Lipczynski K. Barriers to adult immunization. Am J Med 2008;121:S28-35. 
10. IDSA Immunization Work Group. Now is the Time to Immunize Adults:Results of an IDSA Survey of Members' Immunization Practices. Available at: http://www.idsociety.org/uploadedFiles/IDSA/Policy and Advocacy/Current Topics and Issues/Immunizations and Vaccines/Adult and Adolescent Immunization/Related Links/Adult\%20Immunization\%20Commentary\%20IDSA7\%20012810\%20Final(1).pdf. Accessed June 2016.

11. Centers for Disease Control Prevention. Use of 13-valent pneumococcal conjugate vaccine and 23-valent pneumococcal polysaccharide vaccine for adults with immunocompromising conditions: recommendations of the Advisory Committee on Immunization Practices (ACIP). MMWR Morb Mortal Wkly Rep 2012;61:816-819.

12. Centers for Disease Control Prevention. Advisory Committee on Immunization Practices (ACIP) recommended immunization schedules for persons aged 0 through 18 years and adults aged 19 years and older--United States, 2013. MMWR Suppl 2013;62:1.

13. Tomczyk S, Bennett NM, Stoecker C, et al. Use of 13-valent pneumococcal conjugate vaccine and 23-valent pneumococcal polysaccharide vaccine among adults aged >/=65 years: recommendations of the Advisory Committee on Immunization Practices (ACIP). MMWR Morb Mortal Wkly Rep 2014;63:822-825.

14. Kobayashi M, Bennett NM, Gierke R, et al. Intervals Between PCV13 and PPSV23 Vaccines: Recommendations of the Advisory Committee on Immunization Practices (ACIP). MMWR Morb Mortal Wkly Rep 2015;64:944-947.

15. ACIP Adult Immunization Work Group, Bridges CB, Woods L, et al. Advisory Committee on Immunization Practices (ACIP) recommended immunization schedule for adults aged 19 years and older--United States, 2013. MMWR Suppl 2013;62:9-19.

16. Soumerai SB, Avorn J. Principles of educational outreach ('academic detailing') to improve clinical decision making. JAMA 1990;263:549-556. 
17. Yeh JS, Van Hoof TJ, Fischer MA. Key Features of Academic Detailing: Development of an Expert Consensus Using the Delphi Method. Am Health Drug Benefits 2016;9:42-50.

18. Pierannunzi C, Hu SS, Balluz L. A systematic review of publications assessing reliability and validity of the Behavioral Risk Factor Surveillance System (BRFSS), 2004-2011. BMC Med Res Methodol 2013;13:49.

19. Centers for Disease Control and Prevention. Invasive Pneumococcal Disease (IPD) (Streptococcus pneumoniae), 2017 Case Definition. Available at https://wwwn.cdc.gov/nndss/conditions/invasive-pneumococcal-disease/casedefinition/2017/. Accessed May 2017.

20. Centers for Disease Control and Prevention. MMWR: Summary of Notifiable Infectious Diseases. Available at: https://www.cdc.gov/mmwr/mmwr nd/index.html. Accessed July 2017.

21. U.S. Census Bureau. American Factfinder. Available at: www.factfinder.census.gov. Accessed May 2017.

22. Dean AG, Sullivan KM, Soe MM. OpenEpi: Open Source Epidemiologic Statistics for Public Health, Version. Available at: www.OpenEpi.com, updated 2013/04/06. Accessed May 2017.

23. Vila-Corcoles A, Ochoa-Gondar O, Hospital I, et al. Protective effects of the 23-valent pneumococcal polysaccharide vaccine in the elderly population: the EVAN-65 study. Clin Infect Dis 2006;43:860-868.

24. Becker-Dreps S, Amaya E, Liu L, et al. Impact of a combined pediatric and adult pneumococcal immunization program on adult pneumonia incidence and mortality in Nicaragua. Vaccine 2015;33:222-227.

25. Wagner C, Popp W, Posch M, et al. Impact of pneumococcal vaccination on morbidity and mortality of geriatric patients: a case-controlled study. Gerontology 2003;49:246-250. 
26. Van Hoof TJ, Harrison LG, Miller NE, et al. Characteristics of Academic Detailing: Results of a Literature Review. Am Health Drug Benefits 2015;8:414-422.

27. Thomas RE, Lorenzetti DL. Interventions to increase influenza vaccination rates of those 60 years and older in the community. Cochrane Database Syst Rev 2014:CD005188.

28. Blitz DA, Mallen JR, Kwiatkowski TG, et al. Not for industry only: medical students and office-based academic detailing the PIVOT (Pregnant women Influenza Vaccine Optimization Team) initiative. Adv Med Educ Pract 2015;6:323-327.

29. Kim CS, Kristopaitis RJ, Stone E, et al. Physician education and report cards: do they make the grade? results from a randomized controlled trial. Am J Med 1999;107:556-560.

30. Pittenger K, Williams BL, Mecklenburg RS, et al. Improving acute respiratory infection care through nurse phone care and academic detailing of physicians. J Am Board Fam Med 2015;28:195-204. 
Table 1. Immunization provider survey of academic detailing, percent agreeing or strongly agreeing, by setting

\begin{tabular}{|c|c|c|c|c|c|c|}
\hline Question & $\begin{array}{l}\text { Community } \\
N=247\end{array}$ & $\begin{array}{c}\text { Ambulatory } \\
\text { care } \\
\mathrm{N}=24\end{array}$ & $\begin{array}{l}\text { Free clinic } \\
\qquad N=4\end{array}$ & $\begin{array}{l}\text { Hospital } \\
\mathrm{N}=55\end{array}$ & $\begin{array}{l}\text { Private } \\
\text { practice } \\
\mathrm{N}=19\end{array}$ & $\begin{array}{l}\text { Other } \\
\mathrm{N}=64\end{array}$ \\
\hline $\begin{array}{l}\text { Q1. My knowledge of } \\
\text { identifying which patient } \\
\text { population requires } \\
\text { PCV13 or PPVSV23 has } \\
\text { improved }\end{array}$ & $95.5 \%$ & $91.7 \%$ & $100.0 \%$ & $89.1 \%$ & $78.9 \% *$ & $82.8 \% *$ \\
\hline $\begin{array}{l}\text { Q2. The educational } \\
\text { material is easy to } \\
\text { understand }\end{array}$ & $94.3 \%$ & $100.0 \%$ & $75.0 \%$ & $76.4 \% *$ & $89.5 \%$ & $73.4 \% *$ \\
\hline $\begin{array}{l}\text { Q3. This academic } \\
\text { detailing session was } \\
\text { effective }\end{array}$ & $96.8 \%$ & $87.5 \%$ & $100.0 \%$ & $85.5 \%$ * & $84.2 \%$ * & $79.7 \% *$ \\
\hline $\begin{array}{l}\text { Q4. As a result of this } \\
\text { education, I am confider } \\
\text { that I can apply this } \\
\text { knowledge in clinical } \\
\text { practice }\end{array}$ & $94.7 \%$ & $87.5 \%$ & $100.0 \%$ & $74.5 \%$ * & $73.7 \%$ * & $62.5 \% *$ \\
\hline $\begin{array}{l}\text { Q5. As a result of this } \\
\text { education, I intend to } \\
\text { apply the vaccination } \\
\text { pathway in my practice }\end{array}$ & $93.9 \%$ & $75.0 \%$ * & $75.0 \%$ & $67.3 \%$ * & $73.7 \%$ * & $59.4 \% *$ \\
\hline $\begin{array}{l}\text { Q6. As a result of this } \\
\text { education, I expect my }\end{array}$ & $82.2 \%$ & $58.3 \%$ * & $100.0 \%$ & $60.0 \% *$ & $68.4 \%$ & $53.1 \% *$ \\
\hline
\end{tabular}




\begin{tabular}{|l|l|l|l|l|} 
vaccination practices to \\
change
\end{tabular}

* Significant $(p<0.05)$ differences as compared with community setting. 
Table 2. Immunization provider survey of academic detailing, percent agreeing or strongly agreeing, by provider

\begin{tabular}{|c|c|c|c|c|c|}
\hline Question & $\begin{array}{c}\text { Pharmacist } \\
\mathrm{N}=278\end{array}$ & $\begin{array}{l}\text { Nurse } \\
\mathrm{N}=95\end{array}$ & $\begin{array}{c}\text { Nurse } \\
\text { Practitioner } \\
\mathrm{N}=4\end{array}$ & $\begin{array}{c}\text { Physician } \\
\text { N }=7\end{array}$ & $\begin{array}{l}\text { Other } \\
N=29\end{array}$ \\
\hline $\begin{array}{l}\text { Q1. My knowledge of } \\
\text { identifying which patient } \\
\text { population requires } \\
\text { PCV13 or PPVSV23 has } \\
\text { improved }\end{array}$ & $96.0 \%$ & $81.1 \% *$ & $100.0 \%$ & $71.4 \% *$ & $89.7 \%$ \\
\hline $\begin{array}{l}\text { Q2. The educational } \\
\text { material is easy to } \\
\text { understand }\end{array}$ & $96.8 \%$ & $61.1 \%$ * & $100.0 \%$ & $100.0 \%$ & $96.6 \%$ \\
\hline $\begin{array}{l}\text { Q3. This academic } \\
\text { detailing session was } \\
\text { effective }\end{array}$ & $96.8 \%$ & $72.6 \%$ * & $100.0 \%$ & $100.0 \%$ & $100.0 \%$ \\
\hline $\begin{array}{l}\text { Q4. As a result of this } \\
\text { education, I am confident } \\
\text { that I can apply this } \\
\text { knowledge in clinical } \\
\text { practice }\end{array}$ & $95.3 \%$ & $65.3 \%$ * & $100.0 \%$ & $100.0 \%$ & $55.2 \%$ * \\
\hline $\begin{array}{l}\text { Q5. As a result of this } \\
\text { education, I intend to } \\
\text { apply the vaccination } \\
\text { pathway in my practice }\end{array}$ & $91.0 \%$ & $73.7 \%$ * & $100.0 \%$ & $85.7 \%$ & $31.0 \%$ * \\
\hline $\begin{array}{l}\text { Q6. As a result of this } \\
\text { education, I expect my }\end{array}$ & $80.2 \%$ & $64.2 \%$ * & $100.0 \%$ & $100.0 \%$ & $24.1 \%$ * \\
\hline
\end{tabular}




\begin{tabular}{|l|l|l|l|l|} 
vaccination practices to \\
change
\end{tabular}

* Significant $(p<0.05)$ differences as compared with pharmacists. 
Table 3. Change in annual rates of pneumococcal disease hospital discharges, Rhode Island

\begin{tabular}{|c|c|c|c|c|}
\hline & $\begin{array}{c}\text { Pre- } \\
\text { intervention } \\
\text { (Jan 1, } 2013 \text { - } \\
\text { Dec 31, 2013) }\end{array}$ & $\begin{array}{l}\text { Intervention } \\
\text { (Jan 1, } 2014 \\
\text { - Sep 30, } \\
\text { 2015) }\end{array}$ & $\begin{array}{c}\text { Rate } \\
\text { difference }\end{array}$ & $\begin{array}{c}\text { 95\% } \\
\text { Confidence } \\
\text { Interval }\end{array}$ \\
\hline $\begin{array}{l}\text { Rhode Island, } \\
\text { pneumococcal disease per } \\
\text { 10,000 discharges }\end{array}$ & 12.8 & 10.0 & $-2.74^{a}$ & $-5.15,-0.32$ \\
\hline $\begin{array}{l}\text { Rhode Island, } \\
\text { pneumococcal disease per } \\
10,000 \text { bed days }\end{array}$ & 2.5 & 2.0 & $-0.50^{a}$ & $-0.98,-0.01$ \\
\hline
\end{tabular}

Source: hospital discharge data.

${ }^{a}$ Comparison of pre-intervention and intervention periods significantly different $(p<0.05)$. 
Table 4. Change in annual rates of invasive pneumococcal disease

\begin{tabular}{|c|c|c|c|c|c|}
\hline & $\begin{array}{c}\text { Pre- } \\
\text { intervention } \\
\text { (Jan 1, } 2013 \text { - } \\
\text { Dec 31, 2013) }\end{array}$ & $\begin{array}{l}\text { Intervention } \\
\text { (Jan 1, } 2014 \\
\text { - Dec 31, } \\
\text { 2015) }\end{array}$ & $\begin{array}{c}\text { Post- } \\
\text { intervention } \\
\text { (Jan 1, } 2016 \\
\text { - Dec 31, } \\
\text { 2016) }\end{array}$ & $\begin{array}{c}\text { Pre-post rate } \\
\text { difference }\end{array}$ & $\begin{array}{l}95 \% \\
\text { Confidence } \\
\text { Interval }\end{array}$ \\
\hline $\begin{array}{l}\text { Rhode Island, invasive } \\
\text { pneumococcal disease per } \\
1,000,000 \text { population }\end{array}$ & 72 & 64 & $51^{a}$ & $-21.06^{a}$ & $-42.25,0.14$ \\
\hline $\begin{array}{l}\text { New England, invasive } \\
\text { pneumococcal disease per } \\
1,000,000 \text { population }\end{array}$ & 47 & $76^{b}$ & $74^{c}$ & $26.35^{c}$ & $20.73,31.98$ \\
\hline $\begin{array}{l}\text { United States, invasive } \\
\text { pneumococcal disease per } \\
1,000,000 \text { population }\end{array}$ & 53 & $49^{b}$ & $45^{c}$ & $-7.78^{c}$ & $-8.87,-6.70$ \\
\hline
\end{tabular}

Source: Morbidity and Mortality Weekly Report data.

${ }^{a}$ Comparison of pre-intervention and post-intervention periods, $p=0.05$.

${ }^{b}$ Comparison of pre-intervention and intervention periods significantly different $(p<0.05)$.

${ }^{c}$ Comparison of pre-intervention and post-intervention periods significantly different $(p<0.05)$. 


\section{Pneumococcal Vaccination Outreach Educational Academic Detailing}

Which choice best describes your health profession?

\begin{tabular}{|c|c|c|c|c|c|}
\hline Physician & $\begin{array}{c}\text { Physician } \\
\text { Assistant }\end{array}$ & $\begin{array}{c}\text { Nurse } \\
\text { Practitioner }\end{array}$ & Nurse & Pharmacist & Other \\
\hline & & & & & \\
\hline
\end{tabular}

Which choice best describes your primary workplace setting?

\begin{tabular}{|c|c|c|c|c|c|c|}
\hline $\begin{array}{c}\text { Ambulatory } \\
\text { care }\end{array}$ & Community & Free clinic & $\begin{array}{c}\text { Government } \\
\text { hospital }\end{array}$ & Hospital & $\begin{array}{c}\text { Private } \\
\text { practice }\end{array}$ & Other \\
\hline & & & & & & \\
\hline
\end{tabular}

Please indicate your degree of agreement with each statement.

\begin{tabular}{|c|c|c|c|c|c|}
\hline & $\begin{array}{l}\text { Strongly } \\
\text { Agree }\end{array}$ & Agree & Neutral & Disagree & $\begin{array}{l}\text { Strongly } \\
\text { Disagree }\end{array}$ \\
\hline $\begin{array}{l}\text { 1. My knowledge of identifying which patient } \\
\text { population requires Prevnar } 13 \AA \text { (pneumococcal } \\
\text { conjugate vaccine; PCV13) or Pneumovax® (23- } \\
\text { valent polysaccharide vaccine; PPVSV23) has } \\
\text { improved. }\end{array}$ & & & & & \\
\hline 2. The educational material is easy to understand. & & & & & \\
\hline 3. This academic detailing session was effective. & & & & & \\
\hline $\begin{array}{l}\text { 4. As a result of this education, I am confident that I } \\
\text { can apply this knowledge in clinical practice. }\end{array}$ & & & & & \\
\hline $\begin{array}{l}\text { 5. As a result of this education, I intend to apply the } \\
\text { vaccination pathway in my practice. }\end{array}$ & & & & & \\
\hline $\begin{array}{l}\text { 6. As a result of this education, I expect my } \\
\text { vaccination practices to change. }\end{array}$ & & & & & \\
\hline
\end{tabular}

Comments for specific questions.

Please use the space below to add overall comments about the academic detailing or educational materials. 


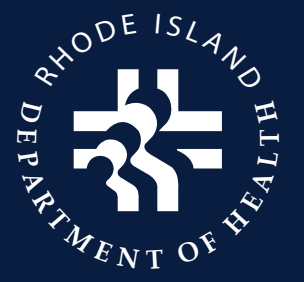

Pneumococcal Vaccination Recommendations Adults $\geq 19$ Years $^{1-4}$

(Including updated recommendations for the use of PCV13 in Adults)

\section{[realthy Adultes 8 G5}

Pneumococcal Vaccination

Naive or Unknown History
Previously vaccinated with PPSV23 at age $\geq 65$

$\geq 1$ year after PPSV23
GIVE: PCV13

Wait $\geq 1$ year*
Previously vaccinated with PPSV23 before age 65

$\geq 1$ year after PPSV23

GIVE: PCV13 if not previously given

Wait $\geq 1$ year*

(and $\geq 5$ years after PPSV23)

GIVE: PPSV23†

GIVE: PCV13 if not previously given

GIVE: PPSV23†

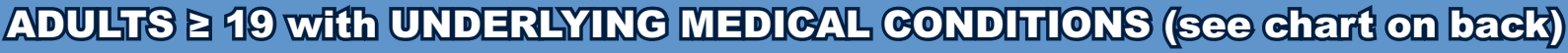
OR who SMONA or tre to a NURSING HOM

Pneumococcal Vaccination

Naive or Unknown History

GIVE: PPSV23

At Age $\geq 65$

GIVE: PCV13 $\geq 1$ year after PPSV23

THEN: PPSV23 $\dagger \geq 1$ year* after

PCV13 and $\geq 5$ years after PPSV23
Previously vaccinated with one dose PPSV23
Vaccination is NOT indicated for healthy persons

19 - 64 years of age

While PCV13 is FDA-approved for persons $>50$ years, the Advisory Committee on Immune Practices does not provide guidance for use in this population.

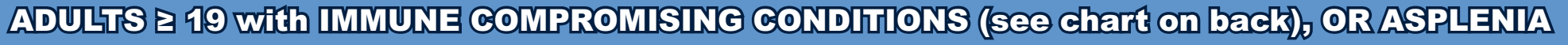

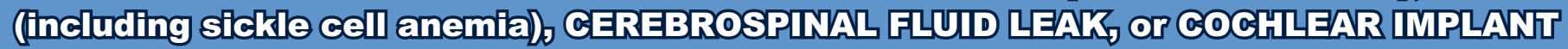

GIVE: PCV13 $\geq 1$ year after PPSV23

THEN: PPSV23 $† \geq 1$ year* after

PCV13 and $\geq 5$ years after PPSV23
Previously vaccinated with one dose PPSV23

Naive or Unknown History

GIVE: PCV13

$\geq 8$ weeks* later

\begin{tabular}{|c|}
\hline If $<65$ \\
GIVE: PPSV23 \\
\hline If $<65$ and \\
$\geq 5$ years after \\
PPSV23 \\
GIVE: second \\
PPSV23 $\$$ \\
\hline
\end{tabular}

At Age $\geq 65$

GIVE: PPSV23

$\geq 5$ years after

PPSV23
If $\geq 65$

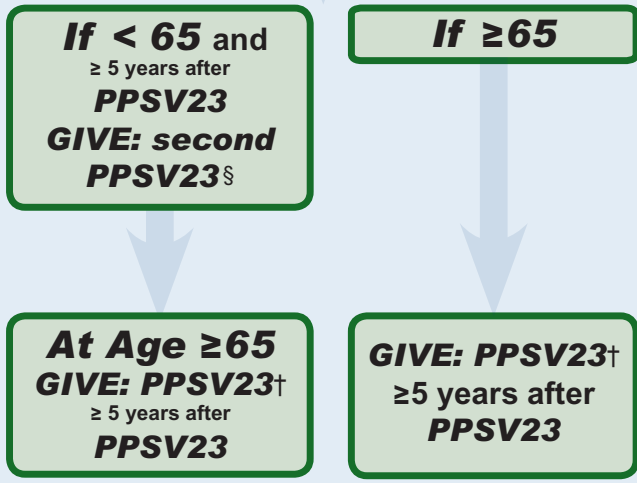

At Age $\geq 65$
GIVE: PPSV23 +
$\geq 5$ years after
PPSV23

GIVE: PPSV23† PPSV23 $\geq 1$ year after PPSV23

GIVE; PCV13 if not previously given

\section{$\geq 8$ weeks* later}

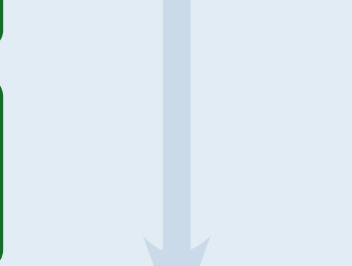

Previously vaccinated with two doses of PPSV23

$\geq 1$ year after PPSV23

GIVE: PPSV23†

\section{At Age $\geq 65$}

GIVE: PPSV23 $\dagger \geq 8$ weeks* after PCV13 and $\geq 5$ years after PPSV23

* Minimum interval between sequential administration of PCV13 and PPSV23 is 8 weeks in immunocompromised patients.

For Medicare reimbursement interval must be 11 full months. Please refer to page 4.

$\dagger$ The ACIP (Advisory Committee on Immunization Practices) recommends only 1 dose of PPSV23 at age $\geq 65$. Revaccination is not necessary.

$\S$ A second PPSV23 for patients with cerebrospinal fluid leak, or cochlear implant is not required.

PPSV23=23-Valent Pneumococcal Polysaccharide Vaccine (Pneumovax ${ }^{\circledR} 23$ ) 


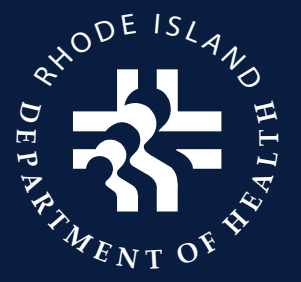

\section{Pneumococoal Vacoination Recommendations Adults $\geq 19$ Years}

(Including updated recommendations for the use of PCV13 in Adults)

PCV13 and PPSV23 Indications for Adults $\geq 19$ Years* by Risk Group 2,3

\begin{tabular}{|c|c|c|c|c|}
\hline \multirow{2}{*}{ Risk Group } & \multirow{2}{*}{ Underlying Medical Condition } & \multirow{2}{*}{$\begin{array}{c}\text { PCV13 (Prevnar13 }{ }^{\circledR} \text { ) } \\
\text { Recommended }\end{array}$} & \multicolumn{2}{|c|}{ PPSV23 (Pneumovax ${ }^{\circledR 23)}$} \\
\hline & & & Recommended & $\begin{array}{l}\text { Revaccinate } 5 \text { years } \\
\text { after first dose }\end{array}$ \\
\hline \multirow{8}{*}{$\begin{array}{l}\text { Persons with normal } \\
\text { immune function }\end{array}$} & Cigarette smoker & & $\checkmark$ & \\
\hline & Chronic heart disease $\dagger$ & & $\checkmark$ & \\
\hline & Chronic lung disease ${ }^{\S}$ & & $\checkmark$ & \\
\hline & Diabetes mellitus & & $\checkmark$ & \\
\hline & Cerebrospinal fluid leak & $\checkmark$ & $\sqrt{ }$ & \\
\hline & Cochlear implant $£$ & $\checkmark$ & $\checkmark$ & \\
\hline & Alcoholism & & $\sqrt{ }$ & \\
\hline & Chronic liver disease, cirrhosis & & $\checkmark$ & \\
\hline \multirow{2}{*}{$\begin{array}{l}\text { Persons with functional or } \\
\text { anatomical asplenia } \\
\text { (Please refer to reference } 3 \text { for } \\
\text { specific guidance.) }\end{array}$} & $\begin{array}{l}\text { Sickle cell disease or other } \\
\text { hemaglobinopathy }{ }^{\infty}\end{array}$ & $\checkmark$ & $\checkmark$ & $\checkmark$ \\
\hline & Congenital or acquired asplenia ${ }^{\infty}$ & $\checkmark$ & $\checkmark$ & $\checkmark$ \\
\hline \multirow{12}{*}{$\begin{array}{l}\text { Immunocompromised } \\
\text { persons } \\
\text { (Please refer to reference } 3 \text { for } \\
\text { specific guidance.) }\end{array}$} & $\begin{array}{l}\text { Congenital or acquired } \\
\text { immunodeficiency" }\end{array}$ & $\checkmark$ & $\checkmark$ & $\checkmark$ \\
\hline & HIV infection & $\checkmark$ & $\sqrt{ }$ & $\sqrt{ }$ \\
\hline & Chronic renal failure & $\checkmark$ & $\checkmark$ & $\checkmark$ \\
\hline & Nephrotic syndrome & $\checkmark$ & $\checkmark$ & $\checkmark$ \\
\hline & Leukemia & $\checkmark$ & $\checkmark$ & $\checkmark$ \\
\hline & Lymphoma & $\checkmark$ & $\checkmark$ & $\checkmark$ \\
\hline & Hodgkin disease & $\checkmark$ & $\checkmark$ & $\checkmark$ \\
\hline & Generalized malignancy & $\checkmark$ & $\checkmark$ & $\checkmark$ \\
\hline & $\begin{array}{l}\text { latrogenic immunosuppression }{ }^{\star *} \\
\text { (Both high and low level immunosuppression) }\end{array}$ & $\checkmark$ & $\checkmark$ & $\checkmark$ \\
\hline & Solid organ transplant & $\checkmark$ & $\checkmark$ & $\checkmark$ \\
\hline & Multiple myeloma & $\checkmark$ & $\checkmark$ & $\checkmark$ \\
\hline & Hematopoietic stem cell transplant & Please refer & eference 3 for spe & uidance \\
\hline
\end{tabular}

$\dagger$ Including congestive heart failure and cardiomyopathies, excluding hypertension.

If feasible, administer PCV13 and PPSV23 $\geq 2$ weeks before planned cochlear implant surgery at appropriate intervals as described in the algorithm on the front page.

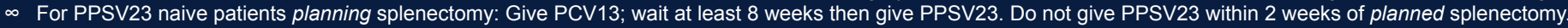

$\S$ Including chronic obstructive pulmonary disease, emphysema, and asthma.

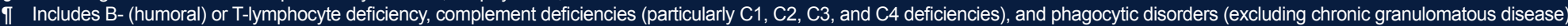

** Those requiring treatment with immunosuppressive drugs, including long-term systemic corticosteroids and radiation.

REFERENCES:

1. Immunization Services Division, National Center for Immunization and Respiratory Diseases, CDC. Advisory Committee on Immunization Practices (ACIP) Recommended Immunization Schedules for Persons Aged 0 Through 18 years and Adults Aged 19 Years and Older - United States, 2013. MMWR Morb Mortal Wkly Rep. 2013;62(Suppl):9-19.

2. CDC. Use of 13-valent pneumococcal conjugate vaccine and 23-valent pneumococcal polysaccharide vaccine for adults with immunocompromising conditions: recommendations of the Advisory Committee on Immunization Practices (ACIP). MMWR Morb Mortal Wkly Rep. 2012;61(40):816-819.

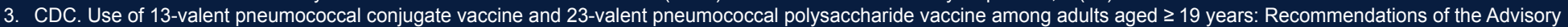
Committee on Immunization Practices (ACIP). MMWR Morb Mortal Wkly Rep. 2014;63(37):822-825.

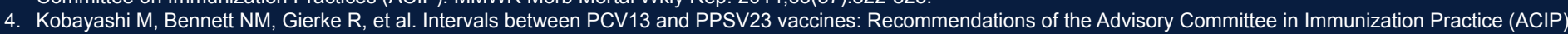
MMWR Morb Mortal Wkly Rep. 2015; 64(34): 944-947.

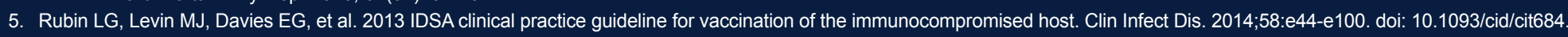




\section{Facts About Pneumococcal Disease:}

- Streptococcus pneumoniae bacteria (i.e., pneumococci) are usually found in the upper respiratory tract of most people.

- Pneumococcal disease most commonly presents as a serious infection in the lungs (pneumonia), blood (bacteremia), or brain (meningitis). The annual U.S. case estimate for invasive pneumococcal disease (bacteremia and/or meningitis) is 40,000 and 4,250 deaths.

- Pneumococcal disease most often occurs in older people as well as in people with a predisposing condition (e.g., immunosuppression, pulmonary disease, heart disease, diabetes). The disease rates for adults in these groups can be more than 20 times those for adults without high-risk medical conditions.

- PPSV23 is $60-70 \%$ effective in preventing serious pneumococcal disease; it does not provide substantial protection against all types of pneumonia (viral and bacterial). It is not a "pneumonia" vaccine.

\section{Frequently Asked Questions:}

\section{Question: Can I get the influenza and pneumococcal vaccines at the same time?}

Yes. These vaccines can be given at the same time. If giving two IM vaccinations, separate by one inch in the body muscle to reduce likelihood of local reactions overlapping.

\section{Question: If patients who are in a recommended risk group for PPSV23 or PCV13 aren't sure if they} have previously received these vaccines, should healthcare providers vaccinate them?

Yes. If patients do not have a documented vaccination history for these two vaccines and their records are not readily obtainable, you should administer the recommended doses. Extra doses will not cause harm to the patient.

\section{Question: Is an egg allergy a contraindication for PCV13 or PPSV23?}

No. Both vaccinations are safe for persons with egg allergies.

\section{Question: If my state has a registry, do I still need to give patients vaccine record cards?}

Yes. Patient-held cards are an extremely important part of a person's medical history. The person may move to an area without a registry, and a personal record may be the only vaccination record available. In addition, even within a state, all healthcare providers may not participate in the registry, and the personal record card would be needed.

\section{Question: My patient has had laboratory-confirmed pneumococcal pneumonia. Does he/she still need to be vaccinated with PPSV23?}

Yes. There are more than 90 known serotypes of pneumococcus (23 serotypes are in the current vaccine). Infection with one serotype does not necessarily produce immunity to other serotypes. As a result, if the person is a candidate for vaccination, he/she should receive it even after one or more episodes of invasive pneumococcal disease.

\section{Question: Why is pneumococcal vaccination recommended for smokers and asthmatics?}

In 2008, the Advisory Committee on Immunization Practices (ACIP) reviewed new information that suggests that asthma is an independent risk factor for pneumococcal disease among adults. ACIP also reviewed new information that demonstrates an increased risk of pneumococcal disease among smokers. Consequently, ACIP recommends to include both asthma and cigarette smoking as risk factors for pneumococcal disease among adults age 19 through 64 years and as indications for PPSV23. 


\section{Pneumococcal Vaccination Information Sheet}

\section{PPSV23 (Pneumovax ${ }^{\circledR 23)}$}

\section{Manufacturer:}

Merck

www.merckvaccines.com/Products/Pneumovax/Pages/home

How Supplied:

$0.5 \mathrm{~mL}$ Single Dose Vial

Multi-Dose (5 dose Vial)

\section{Storage and Handling:}

Refrigerate on Arrival

Store at $2^{\circ} \mathrm{C}$ to $8^{\circ} \mathrm{C}$

DO NOT FREEZE

Discard after the expiration date

\section{Special instructions:}

None

\section{Route of Administration:}

$0.5 \mathrm{~mL} I \mathrm{M}$ or SQ
PCV13 (Prevnar13®)

\section{Manufacturer:}

Pfizer

http://www.pfizerpro.com/hcp/prevnar13

\section{How Supplied:}

Prefilled Syringe

(10 per Package)

\section{Storage and Handling:}

Refrigerate on Arrival

Store at $2^{\circ} \mathrm{C}$ to $8^{\circ} \mathrm{C}$

DO NOT FREEZE

Discard after the expiration date

\section{Special instructions:}

Shake well to obtain a homogeneous white suspension

Route of Administration:

$0.5 \mathrm{~mL}$ IM ONLY

\section{Insurance Carrier Information:}

\section{Medicare www.medicarenhic.com 1-866-801-5304*}

\section{BCBS of RI www.bcbsri.com/providers 401-274-4848 1-800-230-9050}

\section{UnitedHealthCare www.unitedhealthcareonline.com 1-877-842-3210}

\section{RI Department of Health State Supplied Vaccination Program www.health.ri.gov/resources/immunization/}

Contraindications and Precautions:

- Do not give PPSV23 or PCV13 to patients who have a history of a serious reaction (e.g., anaphylaxis) after a previous dose of PCV13, PPSV23, or one of their components.

- Do not give PPSV23 and PCV13 simultaneously. For vaccine naive patients, give PCV13 first, followed by a dose of PPSV23 $\geq 1$ yeart (unless patient in a population specified by ACIP to require shorter interval, see page 1). For patients who have already received PPSV23, give PCV13 12 months after the most recent dose of PPSV23.

- Vaccine Co-administration: (1) all vaccines used for routine vaccination in the United States can be given on the same day; (2) an inactivated vaccine can be administered either on the same day as or at any time before or after another inactivated or a live vaccine; and (3) any 2 LIVE vaccines that are not given on the same day must be spaced at least 4 weeks apart. Zoster vaccine is a live, attenuated vaccine; injectable influenza vaccine and pneumococcal polysaccharide vaccine are inactivated vaccines. So these 3 vaccines can be given on the same day or at any time before or after each other. They should be given as separate injections, not combined in the same syringe.

\section{Side Effects:}

- Most common side effects from either PPSV23 or PCV13 are soreness and redness at the injection site, lasting 1-2 days.

\section{Drug Information Services 401-874-9188}

